\title{
The Wisdom of Crowds (Vox Populi) and Antidepressant Use
}

\author{
Scott B. Patten*
}

Department of Community Health Sciences, University of Calgary, Canada

\begin{abstract}
Under certain conditions, groups of people may (collectively) make better judgments than experts. Galton connected this phenomenon to the phrase vox populi in a 1907 paper. Arguably, an example of the phenomenon may be found in recent stabilization of the frequency of antidepressant use, following decades of increases. There is no evidence that a change in physician behaviour has caused this stabilization. The stable frequency more likely reflects decisions made by thousands of individual people based on their personal experiences. This may provide a statement from the vox populi on an optimal frequency of antidepressant use in contemporary populations under current conditions, a topic that has eluded the consensus of experts.
\end{abstract}

Keywords: Antidepressant medications, major depression, medication use, monitoring, pharmacoepidemiology, population health.

\section{INTRODUCTION}

In 1907, Francis Galton published a paper exploring whether a crowd could be intelligent. His analysis used entries submitted to a contest held at an agricultural fair in Plymouth, England [1]. The participants, many of whom were butchers and farmers, competed at judging how much a "fat ox" would weigh after it had been slaughtered and dressed. They wrote their estimates on cards, which were later loaned to Galton for analysis. There were 787 eligible entries. The median value of these estimates (what Galton called the "middlemost estimate") was 1207 pounds, amazingly close to the actual weight of the dressed ox: 1198 pounds. Although the individual estimates varied widely, they had a central tendency very close to the true value. Even though the contestants made errors, some guessing too high and others guessing too low, the "vox populi" seemed to produce an estimate that was better than what could be expected from any individual expert.

Galton's idea has recently been popularized by a book by James Surowiecki, called the Wisdom of Crowds [2]. Surowiecki summarized the concept as follows: "under the right circumstances, groups are remarkably intelligent, and are often smarter than the smartest people in them." Surowiecki posited that there are four conditions in which groups can make intelligent judgments: (1) there should be a diversity of opinion within the group, (2) there should be independence of judgment, such that people's opinions are not determined by the opinions of those around them, (3) there should be decentralization, such that people are able to specialize and draw on local knowledge and (4) there must be aggregation: some mechanism must exist for turning these many private judgments into a collective decision. In Galton's example, there was a diversity of opinion within the

*Address correspondence to this author at the $3^{\text {rd }}$ Floor TRW Building, 3280 Hospital Drive N.W., Calgary, Alberta, Canada. T2N 4Z6;

Tel: +1.403.220.8752; Fax: + 1.403.270.7307;

E-mail: patten@ucalgary.ca group, independence of judgment (since the attendees wrote down their answers privately on cards and were, in Galton's words "uninfluenced by oratory and the like"), people were able to draw upon local knowledge and their own experience. By compiling their responses and calculating the median, Galton's calculations provided a mechanism for aggregation.

How does the wisdom of crowds emerge? Surowiecki asserts that each person's guess (in the case of the ox's weight) has two components: information and error. By aggregating a large number of guesses, the errors may cancel themselves out, leaving an informative signal. This type of informationdistilling dynamic is familiar to epidemiologists, who aggregate (through measures of association) large numbers of independent observations in order to detect clear signals of exposure-disease associations.

In psychiatric pharmacoepidemiology, the wisdom of crowds concept is interesting because it provides a novel perspective on longstanding a controversy about the appropriateness of medication use. Theoretically, an observed rate may be too high or too low. However, the pharmacoepidemiologic literature in psychiatry seems to be characterized by "camps" in which like-minded experts form and express polarized opinions. A case in point is the frequency of use of antidepressant medications in populations. This frequency has been estimated from data arising from numerous psychiatric epidemiological surveys. In a recent issue of the British Medical Journal, Dowrick and Frances argued that the frequency of use was far too high [3], an opinion endorsed in an accompanying editorial by Godlee [4], but the same opinion was harshly criticised in subsequent correspondence by Sigalas et al., [5] and others. This exchange represents an example of divergent opinions held by experts, all of whom seem to be guided by strongly held beliefs that shape their interpretation of available data. Small groups of like-minded experts are influenced by each other's view and opinions and they tend to hold similar biases. These "camps" are the opposite of Galton and Surowieki's wise crowds. 


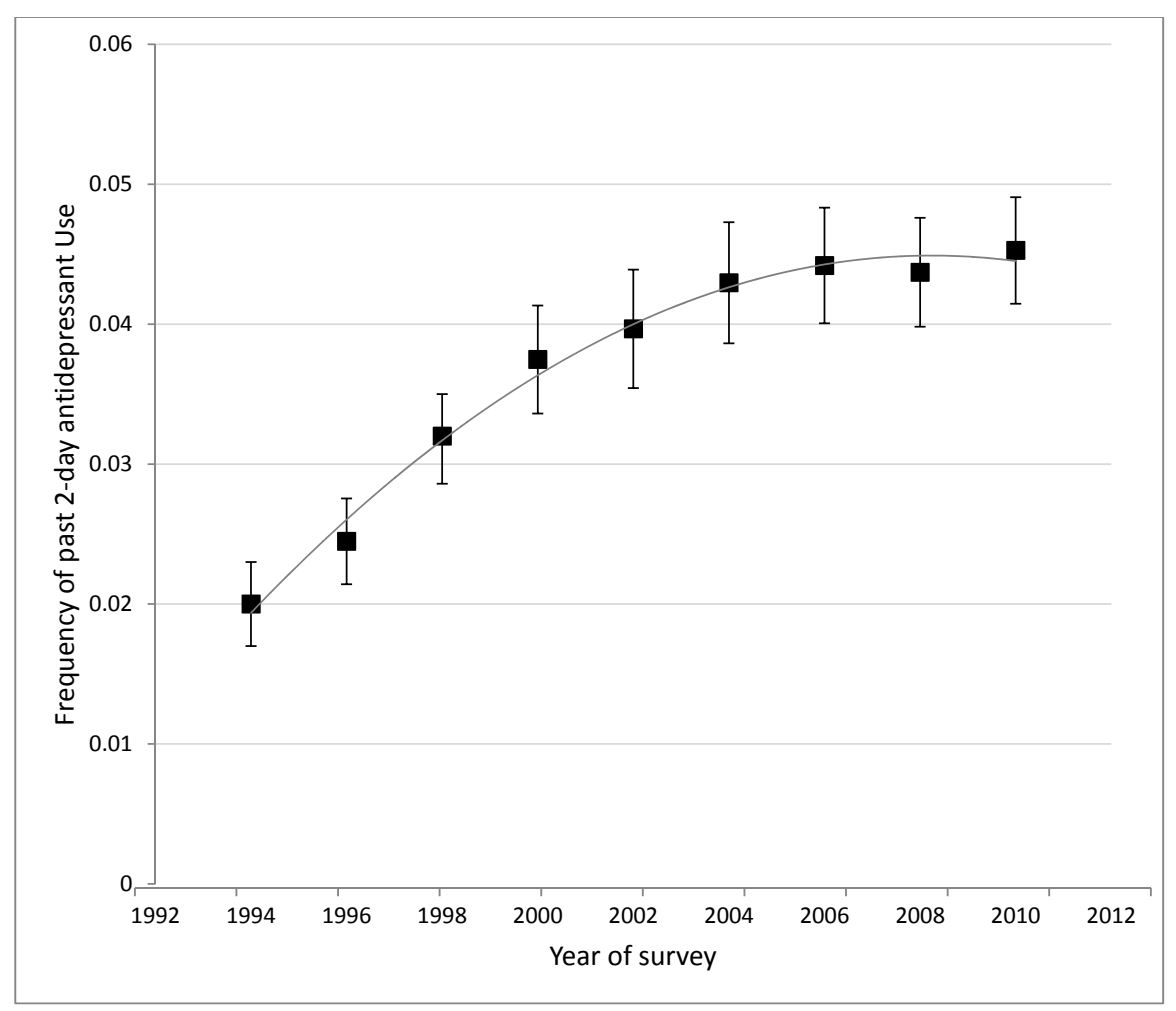

Fig. (1). *Past 2-day antidepressant use in the National Population Health Survey 1994-2010. *Reproduced with permission of the Canadian Psychiatric Association, from Patten et al. [7]. The grey line is a polynomial regression.

What is the best rate of use of antidepressants in a population? Can experts really decide what this should be? The rate of new use of antidepressants stopped increasing several years ago, and the main driver of increased prescriptions in recent years has been a longer duration of use [6]. In other words, the main drivers of the prevalence of antidepressant use are decisions made by thousands of people (and probably to a much lesser extent by their physicians), concerning how long they want to take these medications. People taking antidepressants frequently address the question of whether the benefits and risks of their medications warrant continued use. These decisions are probably more strongly influenced by their specialized personal experiences with the medications than they are influenced by the debates of experts or provocative publications in the medical literature. In other words, these decisions are decentralized. This is not to say that individual people do not have biases for or against the use of medications, however, they probably have a diversity of viewpoints and experiences to draw upon. Some may hate taking medications and may avoid them if at all possible. Others may accept them too readily. The decisions are likely made, to a large extent, independently of those other thousands of people who make similar private decisions about the value of these medications.

An emerging steady state in antidepressant use may very well reflect the wisdom of the vox populi. We have recently reported the emergence of a steady state for antidepressant use in Canada [7]. We examined a series of population sur- veys, finding that the frequency of use increased in the late 1990 s but that it subsequently flattened out and has not increased during the past 10 years. The pattern is depicted in Fig. (1). In the psychiatric literature, the frequency of antidepressant use has often been reported as a means of tracking progress against under-treatment of depression [8]. However, in a steady state scenario, such estimates may serve more as an aggregator than a report card.

The vox populi has several implications for interpretation of pharmacoepidemiological estimates. First, it predicts that the increased use of antidepressants, which has been reported in many countries, will not continue forever. At some point a diversity of experiences with these medications will result in a stabilized mean duration of use which will translate into a stabilized frequency in the population. This can be predicted based on the principal that prevalence (more specifically the prevalence odds) is equal to the product of incidence (of new use) and the mean duration of use.

Personal decisions about medications are not determined solely by their effectiveness and tolerability. Such decisions are also influenced by the skill with which they are prescribed and their adverse effects as well as issues such as stigma, mental health literacy and the costs and inconvenience of taking medications. Another factor may be the availability (and effectiveness) of alternative treatments such as psychotherapy. The ideal rate of antidepressant use may therefore be declared by the vox populi in situations in which clinical settings are populated by skilled clinicians, where 
there is little stigma about mental illness, where costs are not a barrier to accessing treatments and where access to the entire spectrum of treatment options is available. In other words, the vox populi may express the ideal rate of antidepressant use under ideal conditions. In doing so, however, the vox populi may offer something more useful than the divisive voices of experts.

\section{CONFLICT OF INTEREST}

The authors confirm that this article content has no conflict of interest.

\section{ACKNOWLEDGEMENTS}

Dr. Patten is a Senior Health Scholar with Alberta Innovates, Health Solutions. He is a member of the Mathison Centre for Research \& Education in Mental Health.

\section{REFERENCES}

[1] Galton F, Vox populi. Nature 1907; 75: 450-1.

[2] Surowiecki J. The wisdom of crowds. New York: First Anchor Books 2005.

[3] Dowrick C, Frances A. Medicalising unhappiness: new classification of depression risks more patients being put on drug treatment from which they will not benefit. BMJ 2013; 347: f7140.

[4] Godlee F. Don't keep taking the tablets. BMJ 2013; 347: f7438.

[5] Sigalas PD, Barkla X, McArdle P. Underdiagnosis of depression in young people. BMJ 2014; 348: g170.

[6] Moore M, Yuen HM, Dunn N, Mullee MA, Maskell J, Kendrick T. Explaining the rise in antidepressant prescribing: a descriptive study using the general practice research database. BMJ 2009; 339: b3999.

[7] Patten SB, Williams JVA, Lavorato DH, Fiest KM, Bulloch AGM, Wang JL. Antidepressant use in Canada has stopped increasing. Can J Psychiatry 2014; 59(12): 609-14.

[8] Patten SB. Progress against major depression in Canada. Can J Psychiatry 2002; 47: 775-80.

(C) Scott B. Patten; Licensee Bentham Open.

This is an open access article licensed under the terms of the Creative Commons Attribution Non-Commercial License (http://creativecommons.org/licenses/by-nc/3.0/) which permits unrestricted, non-commercial use, distribution and reproduction in any medium, provided the work is properly cited. 